\title{
Analysis of the Economic Benefits of Tianjin County Based on DEA Method
}

\author{
Tian Tian \\ School of Economics and Management \\ Inner Mongolia University \\ Hohhot, P. R. China \\ e-mail:shiyiyue23i@163.com
}

Jianye An

College of Science

Tianjin University of Commerce

Tianjin, P. R. China

e-mail: 273159460@qq.com

\author{
Zhanxin $\mathrm{Ma} *$ \\ School of Economics and Management \\ Inner Mongolia University \\ Hohhot, P. R. China \\ e-mail: man96918@163.com \\ *Corresponding author \\ Ting Wang \\ School of Economics and Management \\ Inner Mongolia University \\ Hohhot, P. R. China \\ e-mail: 704969806@qq.com
}

\begin{abstract}
The county economy is very important in the overall economic development, so the county economic benefits more and more get the attention of government. With the rapid development of China's economy, the county economic efficiency and quality will become an important issue of economic research,therefore, the economic benefits of the district and county of Tianjin have become very meaningful. At first, we give a model for analyzing the county economic benefits by using generalized DEA theory in this paper, it reflects the economic benefit of the unit from five aspects. Then we calculate and analyze the economic benefits of various districts and counties in Tianjin from 2004 to 2103 by use above model. At the same time, we give a comparative study of the economic benefits of $\mathbf{1 6}$ districts in Tianjin. Finally, we find that most of the county's economic development benefits are showing a downward trend, we provide some suggestion on how to improve the economic benefits of Tianjin.
\end{abstract}

Keywords-regional economic; comprehensive evaluation; multi-objective decision-making; general data envelopment analysis; decision making unit

\section{INTRODUCTION}

Tianjin as the economic center in the north and coastal open cities, the gateway to the capital Beijing, only in their own economic rapid and stable, under the premise of sustainable development,it can be better for Bohai Bay Rim area economy and enclose to the role of demonstration and service. Therefore, the balanced and stable development of the regional economic level in the region has a vital impact on the long-term development and the overall planning of Tianjin city. In the new normal economic situation in China, if we want to improve the vitality and competitiveness of economic development to a new level, we should change the existing economic development mode. In this article through the 16 districts in Tianjin economic benefits to make comprehensive evaluation and found deficiencies in the operation of the economy, based on these problems, seek to develop new ideas, make Tianjin city economy to and direction of development of fast and good.

The data envelopment analysis[1-4] is a comprehensive evaluation method for the decision making units, which is the relative efficiency between the decision units and the decision units., According to actual application of rapid development, the traditional DEA model to explain the economic mainly rely on in the production function of economics theory, in the evaluation with the economic benefit of time series did not take into account the technology progress, and the generalized DEA method the decision unit and the sample unit is separated, the analysis and evaluation of decision making units.[5-10] Applying generalized DEA theory knowledge to the study, by using the research method of DEA model, on the basis of the sample unit 2013 economic data and constructs as the evaluation standard and using the section data structure model to evaluate the various districts and counties in Tianjin of economic development benefits and comparative study from 2004 to 2013.

\section{INDEX SELECTION AND MEASUREMENT METHOD}

The economic benefit is the core of all economic activities, and it is the comparison of various consumption and results in the economic activity, and the economic benefit is the important index to evaluate whether an economic activity should be. This paper from five aspects of the measure indexes of selected area per capita GDP, regional capital output rate, area of Industrial Enterprises above Designated Size labor productivity, area above scale industrial enterprises capital output ratio, area per capita total retail sales of consumer goods such as macroeconomic benefit indicators to be studied.

(1) Regional per capita GDP 
Regional per capita gross product ( $L R$ ) is a measure of economic development, and is an effective tool to grasp and meet the macroeconomic situation of the next region.. According to the ratio of the total GDP of the region and the number of household registered in the same period of a certain period, that is:

Per capita GDP = one time the region's GDP/at the same time registered residents in the region

(2) The regional capital-output ratio

Regional capital output rate $(K R)$ is a reflection of the economic benefits of financial investment, is a comprehensive evaluation of the comprehensive index of investment efficiency, If area capital output rate is high, the benefits of economic development in the region is better. According to the ratio of gross domestic product in the region and the total amount of fixed assets in the region of a certain period of time, that is :

Regional capital-output ratio $=$ one time the region's GDP/at the same time the total fixed assets formation in the region

(3) Regional industrial enterprises above designated size in labor productivity

The labor productivity of Industrial Enterprises above Designated Size ( $H R$ )refers to the ratio of the labor consumption created by the workers of the industrial enterprises in a certain period to the labor consumption ratio. The higher labor productivity shows the higher the development level of the social productive forces.. According to the ratio of the total industrial enterprises' production value and the size of the industrial enterprises' employment in the same period.

Regional scale industrial enterprise labor productivity $=$ certain period of the above scale of the industrial enterprise GDP total / while the size of the region above the number of industrial enterprises

(4) Regional industrial enterprises above designated size capital-output ratio

Area of Industrial enterprises above designated Size capital output rate $(M R)$ is a measure of economic benefit of Industrial enterprises above designated size of financial input, and can according to a certain period of time the area of Industrial enterprises above designated size and GDP of the same period of Industrial Enterprises above Designated Size in the region total assets ratio to calculate, that is :

Regional scale industrial enterprise capital output rate $=$ certain period of the above scale of the industrial enterprise GDP total and the same period of the above scale of the industrial enterprise assets of the region

(5) Per capita total retail sales of consumer goods

The total retail sales of social consumer goods is the most direct data of domestic consumption demand.. Total retail sales of social consumer goods is the total consumption of urban and rural residents and social groups by the national economy. Per capita total retail sales of consumer goods ( $R R$ )reflect the level of per capita consumption of a region, according to the ratio of a period of total retail sales of social consumer goods in the region with the same period in the area of household registration number to calculate, that is:

Per capita total retail sales of consumer goods $=$ total retail sales of consumer goods in the region / = a period at the same time registered residents in the region
The economic benefit is the core of all economic activities, and it is the comparison of various consumption and results in the economic activity, and the economic benefit is the important index to evaluate whether an economic activity should be. This paper from five aspects of the measure indexes of selected area per capita GDP, regional capital output rate, area of Industrial Enterprises above Designated Size labor productivity, area above scale industrial enterprises capital output ratio, area per capita total retail sales of consumer goods such as macroeconomic benefit indicators to be studied.

\section{A MEASUREMENT MODEL FOR COMPREHENSIVE EVALUATION OF ECONOMIC BENEFITS OF COUNTY}

Hypothesis was evaluated in terms of the $j$ th area (decision making units) of the $i$ th annual GDP is $Y_{\mathrm{j}}^{(i)}$, the number of household registration is $L_{j}^{(i)}$, fixed capital formation total is $K_{j}^{(i)}$, production value of Industrial Enterprises above designated size is $G_{j}^{(i)}$, above scale industrial enterprises in employment for $H_{j}^{(i)}$, above scale industrial enterprises assets total value of $M_{j}^{(i)}$, total retail sales of social consumer goods is $R_{j}^{(i)}$. According to the above a total per capita GDP, total capital output ratio, industrial labor productivity, industrial capital output ratio, total retail sales of social consumer goods measurement method follows the formula can be obtained.

The total per capita GDP of the $j$ th region in the $i$ th year is

$$
L R_{j}^{(i)}=\left(Y_{j}^{(i)} / L_{j}^{(i)}\right) \times 100 \% .
$$
is

The capital output rate of the $j$ th region in the $i$ th year

$$
K R_{j}^{(i)}=\left(Y_{j}^{(i)} / K_{j}^{(i)}\right) \times 100 \% .
$$

The enterprises above designated size for productivity of the $j$ th region in the $i$ th year is

$$
H R_{j}^{(i)}=\left(G_{j}^{(i)} / H_{j}^{(i)}\right) \times 100 \% ;
$$

The industrial enterprises above designated size capital-output ratio of the $j$ th region in the $i$ th year is

$$
M R_{j}^{(i)}=\left(G_{j}^{(i)} / M_{j}^{(i)}\right) \times 100 \% .
$$

The capita total retail sales of social consumer goods of the $j$ th region in the $i$ th year is

$$
R R_{j}^{(i)}=\left(R_{j}^{(i)} / L_{j}^{(i)}\right) \times 100 \% .
$$

If the selected sample unit (i.e. the reference set) is composed of 1 units, then sample unit in the jth year in the gross domestic product, household registration number, fixed capital formation total, more than the size of the total industrial output value, employment in the industrial enterprises above Designated Size, above scale industrial enterprises in total assets, social total retail sales of consumer goods value are

$\left(Y_{k}^{\left(j_{0}\right)}, L_{k}^{\left(j_{0}\right)}, K_{k}^{\left(j_{0}\right)}, G_{k}^{\left(j_{0}\right)}, H_{k}^{\left(j_{0}\right)}, M_{k}^{\left(j_{0}\right)}, R_{k}^{\left(j_{0}\right)}\right), k=1, \ldots, n^{(0)}$, then according to the theory of generalized ${ }^{[5-7]}$ DEA can establish the following regional economic benefit comprehensive evaluation model: 


$$
\text { (QX) }\left\{\begin{aligned}
\max & \varphi_{j}^{(i)}+\varepsilon\left(s_{1 j}^{(i)}+s_{2 j}^{(i)}+s_{3 j}^{(i)}+s_{4 j}^{(i)}+s_{5 j}^{(i)}\right) \\
\text { s.t. } & \sum_{k=1}^{n^{(0)}}\left(Y_{k}^{(0)} / L_{k}^{(0)}\right) \lambda_{k j}^{(i)}-s_{1 j}^{(i)}=\varphi_{j}^{(i)} Y_{j}^{(i)} / L_{j}^{(i)} \\
& \sum_{k=1}^{n^{(0)}}\left(Y_{k}^{(0)} / K_{k}^{(0)}\right) \lambda_{k j}^{(i)}-s_{2 j}^{(i)}=\varphi_{j}^{(i)} Y_{j}^{(i)} / K_{j}^{(i)} \\
& \sum_{k=1}^{n^{(0)}}\left(G_{k}^{(0)} / H_{k}^{(0)}\right) \lambda_{k j}^{(i)}-s_{3 j}^{(i)}=\varphi_{j}^{(i)} G_{j}^{(i)} / H_{j}^{(i)} \\
& \sum_{k=1}^{n^{(0)}}\left(G_{k}^{(0)} / M_{k}^{(0)}\right) \lambda_{k j}^{(i)}-s_{4 j}^{(i)}=\varphi_{j}^{(i)} G_{j}^{(i)} / M_{j}^{(i)} \\
& \sum_{k=1}^{n^{(0)}}\left(R_{k}^{(0)} / L_{k}^{(0)}\right) \lambda_{k j}^{(i)}-s_{5 j}^{(i)}=\varphi_{j}^{(i)} R_{j}^{(i)} / L_{j}^{(i)} \\
& \sum_{k=1}^{n^{(0)}} \lambda_{k j}^{(l)}=1, s_{1 j}^{(l)} \geq 0, s_{2 j}^{(l)} \geq 0, s_{3 j}^{(l)} \geq 0 \\
& s_{4 j}^{(l)} \geq 0, s_{5 j}^{(l)} \geq 0, k=1,2, \cdots, n^{(0)} \\
& \varepsilon
\end{aligned}\right.
$$

Among them, $\mathcal{E}$ is the Archimedes dimensionless.

Definition 1 if the optimal solution of model (QX) is $\bar{\varphi}_{j}^{(i)}, \stackrel{-(i)}{s_{1 j}}, \stackrel{-(i)}{s_{2 j}}, \stackrel{s}{s i}_{3 j}, s_{4 j}^{(i)}, s_{5 j}^{(i)}, \bar{\lambda}_{k j}^{(i)}, k=1,2, \cdots n^{(0)}$ among

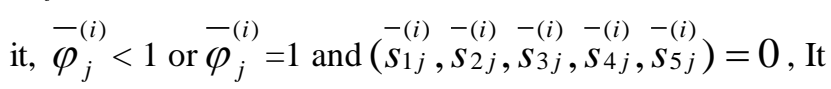
is said that the $j$ th region in the $i$ th year the economic benefits is effective.

Definition 2 If make $E \mathrm{p}_{j}^{(i)}=1 / \bar{\varphi}_{j}^{(i)}$, then called $E p_{j}^{(i)}$ is economic benefits of the relative to the measurement of the base year in the $j$ th region of the $i$ th year.

Remember

$$
\begin{aligned}
& \left(\Delta L R_{j}^{(i)}, \Delta K R_{j}^{(i)}, \Delta H R_{j}^{(i)}, \Delta M R_{j}^{(i)}, \Delta R R_{j}^{(i)}\right) \\
& =\left(\varphi_{j}^{(i)}-1\right)\left(\frac{Y_{j}^{(i)}}{L_{j}^{(i)}}, \frac{Y_{j}^{(i)}}{K_{j}^{(i)}}, \frac{G_{j}^{(i)}}{H_{j}^{(i)}}, \frac{G_{j}^{(i)}}{M_{j}^{(i)}}, \frac{R_{j}^{(i)}}{L_{j}^{(i)}}\right)+\left(s_{1 j}^{(i)}, s_{2 j}, s_{3 j}, S_{4 j}, S_{5 j}\right)
\end{aligned}
$$

If the economic benefit of the region in $i$ th year is invalid, then the economic benefit index $\begin{array}{ll}\left(L R_{j}^{(i)}, K R_{j}^{(i)}, H R_{J}^{(\mathrm{i})}, M R_{j}^{(i)}, R R_{j}^{(i)}\right) & \text { add } \\ \left(\Delta L R_{j}^{(i)}, \Delta K R_{j}^{(i)}, \Delta H R_{j}^{(i)}, \Delta M R_{j}^{(i)}, \Delta R R_{j}^{(i)}\right) & \text { can }\end{array}$ achieve economic benefit effectively, namely become "the best" base year levels.

Seen from the above model, the (QX) from per capita GDP, capital output rate and industrial labor productivity, industrial enterprises and the capital output ratio, per capita total retail sales of consumer goods in five aspects reflect the evaluated the economic benefit of the unit, and can calculate the need to improve the direction and scale, it is helpful for the development of economic benefits.

\section{AN EMPIRICAL ANALYSIS OF THE ECONOMIC DEVELOPMENT BENEFIT OF THE COUNTIES IN TIANJIN}

In this paper, using the above model, the economic benefits of 16 counties in Tianjin are analyzed, and the relevant conclusions are drawn.

First of all ,the data is from the "Tianjin City Statistical Yearbook" database,we collected 16 counties in Tianjin from2004 to 2013 of GDP (unit: million yuan), household population (unit: 10000 people), fixed assets amount (unit: million yuan), industrial enterprises above Designated Size output (unit: million yuan), the number of Industrial Enterprises above Designated Size employment (10 000 persons), above scale industrial enterprises in total assets (100 million yuan), social retail sales of consumer goods (100 million yuan) etc. related data; Secondly, in order to make the data of different years comparable, after deducting inflation factors, all data will be converted to the same the price of 2004; then, according to the model about the total per capita GDP, the total capital output ratio, industrial labor productivity, industrial capital output ratio, per capita total retail sales of social consumer goods to calculate the correlation values. Overall analysis of the overall economic development benefit of Tianjin

According to the data obtained from the calculation, using the model, taking the economic development benefit of 16 districts and counties in 2013 in Tianjin as sample unit,we can obtain the comprehensive economic development benefit measurement value of 16 counties in 2004-2013. When the benefit value is equal to 1 , the economic development of the county is the best level of the 2013; when the benefit value is more than 1, the economic development of the county is better than the best level in 2013; when the benefit value is less than 1, the comprehensive economic benefit value of the district is inferior to the best level in 2013, the number is higher and the level is better. Figure 1 shows the average benefit development measure value of the county's counties in Tianjin from 2004 to 2013.

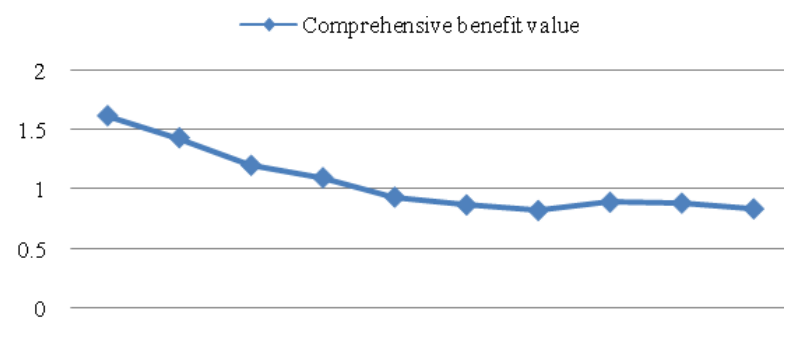

2004200520062007200820092010201120122013

Figure 1. The comprehensive development benefit measurement value of each county in Tianjin from 2004 to 2013

From Figure 1 it can be seen that Tianjin comprehensive development benefit metric value in addition to slightly small amplitude recovery in 2011 and 2012, the values of the other years are in a downward trend, shows that although in recent years, economic growth is rapid, but comprehensive economic development efficiency and quality is declining year by year, in 04-09 
year the value declined faster, in recent years, it become slow down, shows that the government has made the adjustment in the relevant situation, have focused on from the pace of development to transfer to speed and quality to pay equal attention to.

A. The overeall analysis of the comprehensive benefit of ecomomic development of the districts and counties in Tianjin

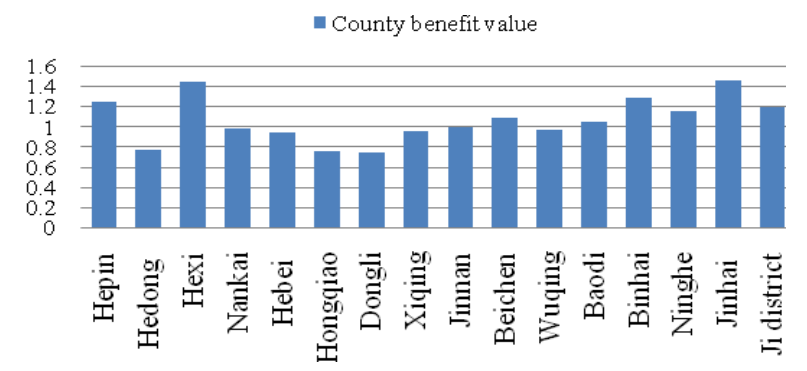

Figure 2. The average value of the development benefit measurement of each county in Tianjin from 2004 to 2013

Figure 2 shows that the average value of the development benefit measurement of 16 counties in Tianjin from 2004 to 2013. From the picture, we can see that the economic benefits of eight districts and counties are higher than 1 , which are better than the best level in 2013 counties, The best of which is Jinghai District, Hexi District, Binhai New District, Heping District, and their economic benefits measurement values are higher than 1.2 it shows that the economic development of these districts is fast and the quality of economic development is better than that the other counties, they should take advantage of the existing situation to supplement their own shortcomings, strive for economic benefits to achieve better. And Hedong District, Hongqiao District, Dongli district are all less than 0.8 , indicating that the economic development of these district are behind other district,they need to focus on optimizing the transformation of economic development, improve the efficiency of economic development, so as to promote the overall economic and healthy development, achieve new progress in the way of economic development..

\section{B. The change of economic development benefit of the counties in Tianjin}

The economic development of various districts and counties in Tianjin is running on the higher growth platform, comprehensive analysis of the economic benefits of various districts and counties is helpful to understand the gap between the districts and helpful to the coordinated development among regions and more conducive to the city's economy stable and rapid development. The following charts show that the comparison between the economic benefit measurement value of 16 counties and the measurement of the total economic benefit of Tianjin City, analysis of the advantages and disadvantages of each county.

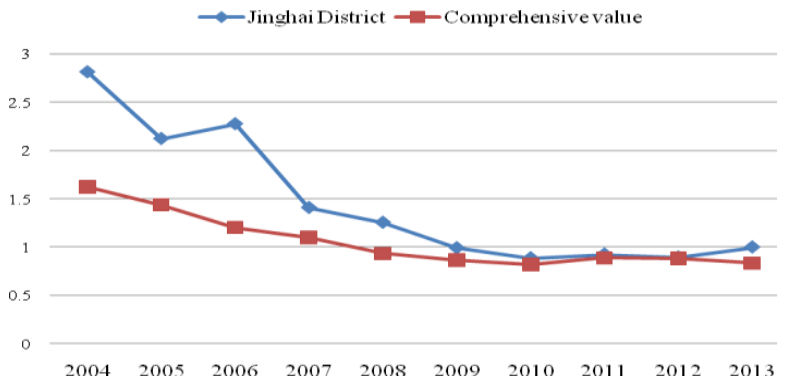

Figure 3. Jinghai benefits change and comparison

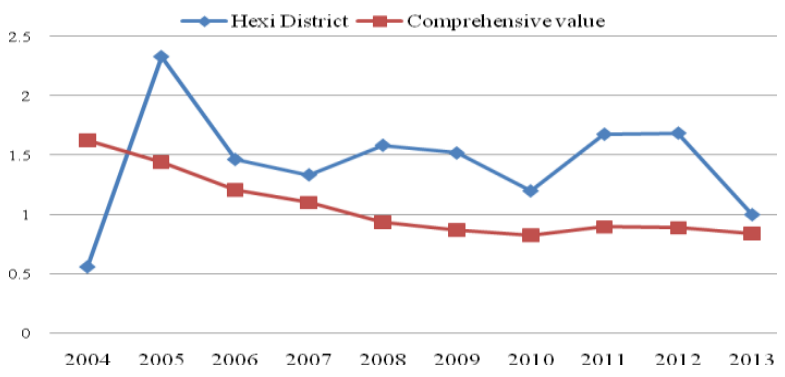

Figure 4. Hexi benefits change and comparison

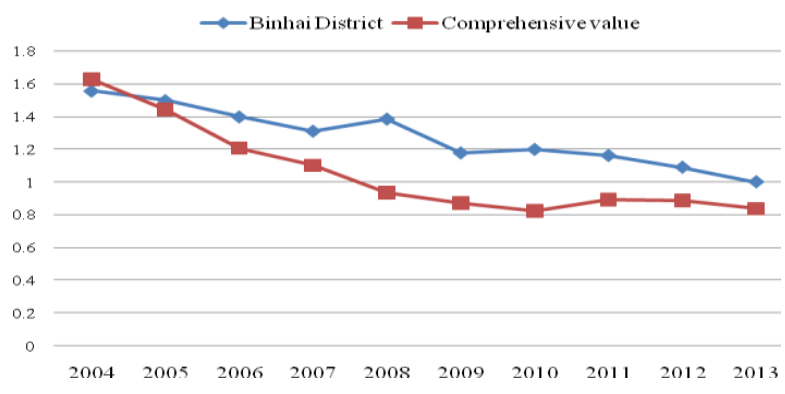

Figure 5. The Binhai new area change and comparison

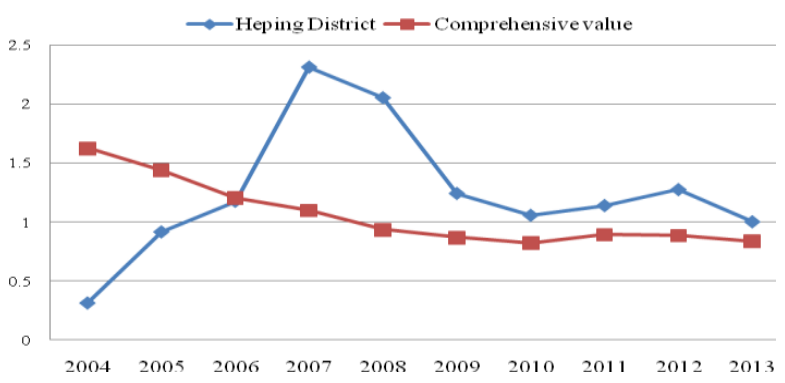

Figure 6. Heping benefits change and comparison

As shown in Figure 3-Figure 6, the average economic efficiency of the four counties can be ranked in the top four in the average economic benefit of 16 counties in Tianjin city, these four counties are Jinghai County, Hexi District, Binhai New Area and Heping District. In 2013, the economic benefit value of these four counties is 1 , it means that the four counties of economic development level is quite in this year and the level is the best. In Figure 3, the economic benefit value of Jinghai county has been in the downward trend. In 2004, the economic 
benefit value is 2.8 which is higher than the comprehensive value but the economic benefit value is 1 in 2013 which is quite compare to comprehensive benefit value. It means that although the economic development of Jinghai County in recent years is at the forefront of Tianjin City, but its economic benefits decreased every year and needed to adjust. In Figure 4, Hexi District in the last 10 years, its changes ups and downs, 04-05 years rapid growth, by less than the comprehensive value to higher than that of the general value, in the next years the value of economic benefit sometimes increases and sometimes decreases, but it is higher than the comprehensive level. In Figure 5, although the economic benefits of Binhai New Area has been declining trend, but compared to other counties it fell by a smaller, has been slightly higher than the comprehensive benefit value of Tianjin City. In Figure 6, it shows that between 04-07 years, the economic benefits of Heping District grows fast, the economic benefit value increased from 0.3 to 2.3 , which its increased 7 times. Compared with the comprehensive benefits of Tianjin City, from 04 years of far below the combined value into 07 years is far higher than the comprehensive value. But, between 07 and 13 years, the Heping Distric economy is in a downward trend, between 10-12 years, the economy has a small recovery, from 07 years of 2.3 to 13 years of 1.3 , gradually almost equivalent to the comprehensive economic benefits of Tianjin City. These four counties in the forefront of economic comprehensive strength is effectively promote the overall economic development of Tianjin City, but in recent years the economic value of the economy has dropped, so need to better play their own advantages industry and better optimize their industrial structure to improve the economic competitiveness.

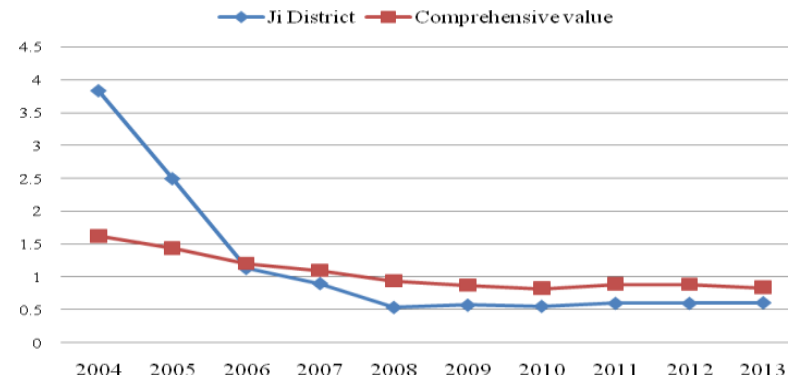

Figure 7. Ji District economic change and comparison

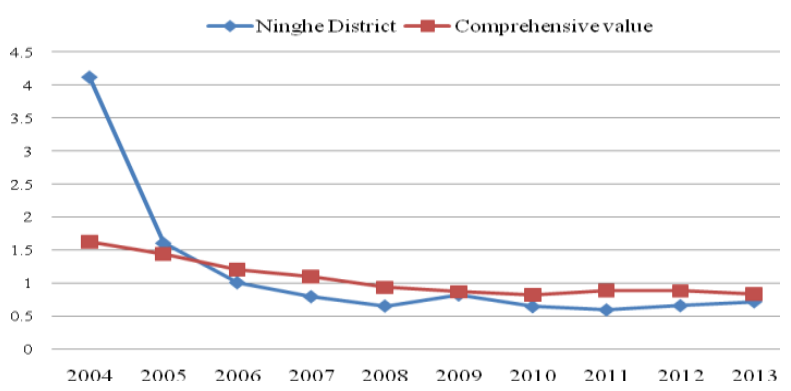

Figure 8. Ninghe economic changes and comparison

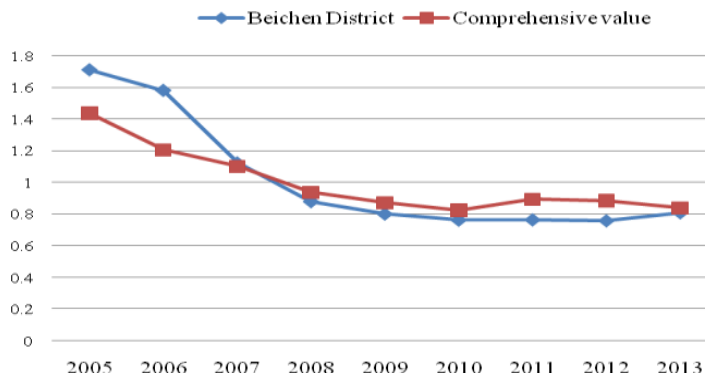

Figure 9. Beichen economic change and comparison

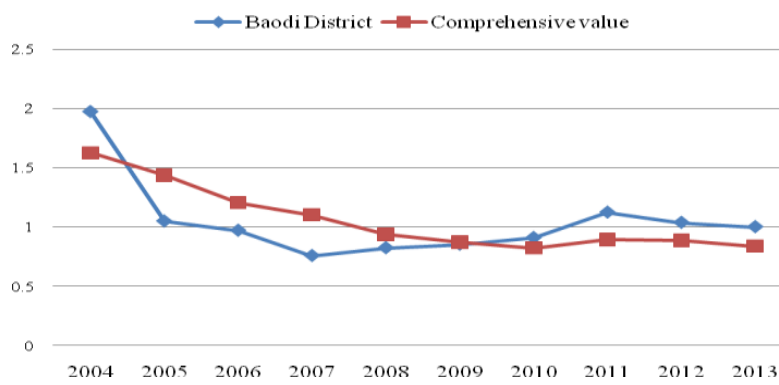

Figure 10. Baodi district economic change and comparison

As shown in Figure 7-Figure 10, there are four counties which are Jixian County, Ninghe County, Beichen District, Baodi District and their average economic benefit is from fourth to eighth. In recent ten years the four district economic benefit measurement value and the comprehensive benefits of Tianjin city are roughly the same, it means that the level of economic development of these four counties is worse than in the preceding four counties, the economic benefit of these four districts is higher than the comprehensive benefit value in 04 years, between 04-06 years there is a relatively large decline, then the downward trend is gradually flat, before 06 years the economic benefit of Ji District was higher than the comprehensive benefit value then have been lower than the overall value of a certain level; except for 04 years, the economic development of other years of Ninghe District is under the overall economic benefit of Tianjin City; before 07 years the economic benefit of Beichen District was higher than the comprehensive benefit value then have been lower than the overall value of a certain level; Baodi District in the last 10 years, its economic benefits have the rise and fall, its economic value is higher in the 04 year, in the 05-09 year, its development level is lower than the comprehensive level; in 10-13 year, its economic efficiency has improved. Although the level of economic development of these four counties is worse than in the preceding four counties, it played a pivotal role in the economic development of Tianjin city. For these four counties, we should pay attention to improve and enrich the advantages of the industry and actively promote the transformation of economic development mode. 


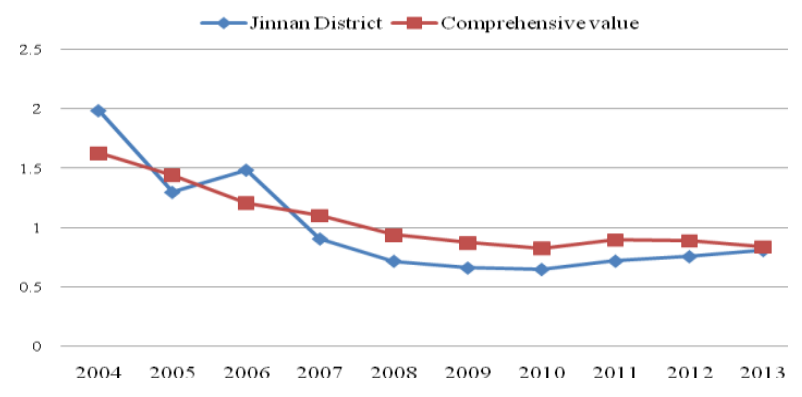

Figure 11. Jinnan economic change and comparison

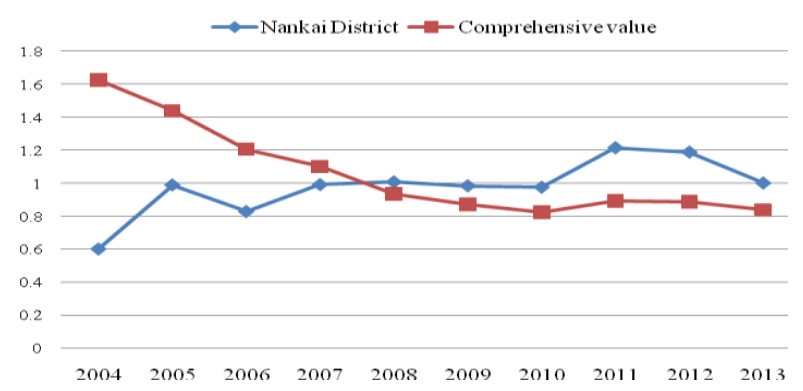

Figure 12. Nankai economic change and comparison

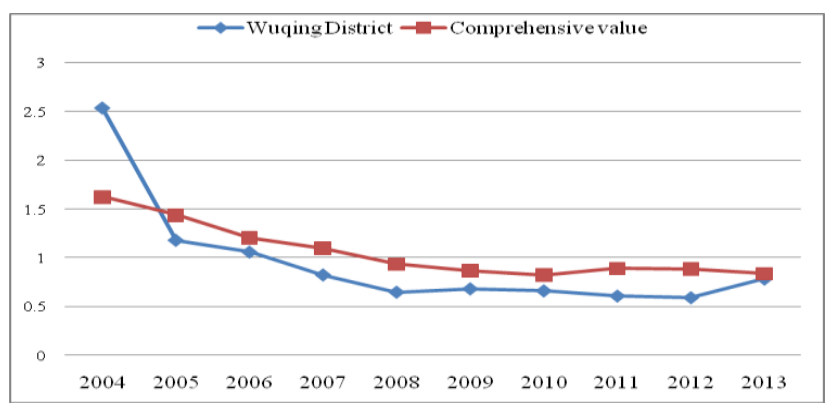

Figure 13.Wuqing economic change and comparison

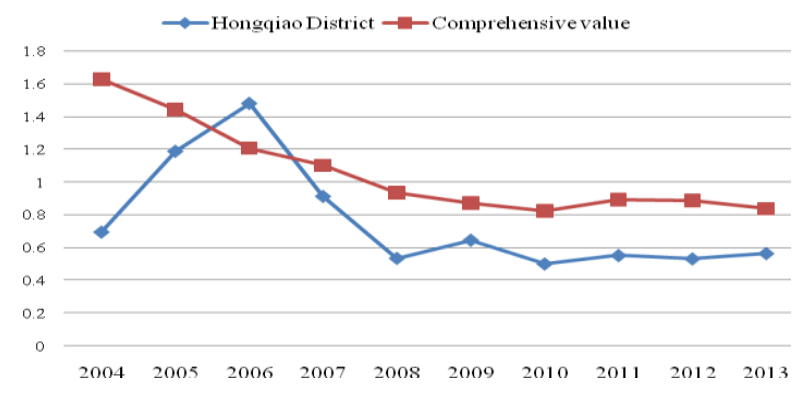

Figure 14. Hongqiao economic change and comparison

As shown in Figure 11-Figure 14, there are four counties which are Jinnan District, Nankai District, Wuqing District, Hongqiao District and their average economic benefit is from ninth to twelfth. The economic development level of these four counties is in the middle and lower level and their economic benefit measurement value is lower than the comprehensive benefit value. 07 years ago, the economic benefit measurement value of the Jinnan Distirct is hovering in the Tianjin city's comprehensive efficiency values, 07 years later it has been lower than the comprehensive benefit value; 07 years ago, the economic benefits of Nankai District is lower than the value of comprehensive benefits, but after 08 years, it's gradually higher than the comprehensive value, it means that in these years, after the implementation of some policies, it has obviously improved the economic benefit of Nankai District, and these experiences should be worthy of other counties for reference; The situation in Wuqing District and Jinnan District is similar, 04 years ago, their economic benefits were good, 05 years later, their level of development began to decline; between 04-06 years, the economic benefit value of Hongqiao District has been in the stage of rapid growth, in the 06 year, it was higher than the comprehensive benefit value, 07 years later, its development level began to fall and it has been lower than the overall level after that. There are some problems in the economic development of the four districts and counties need to be resolved urgently, in order to prevent the sustained decline in economic efficiency we should actively optimize the industrial structure and reform and improve the economic management system.

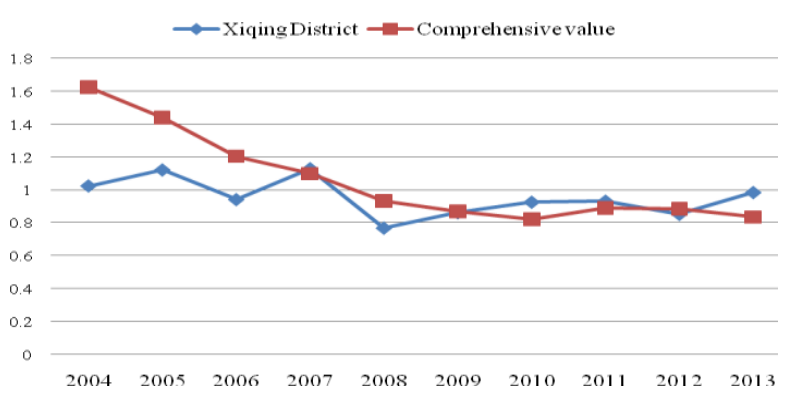

Figure 15. Xiqing economic change and comparison

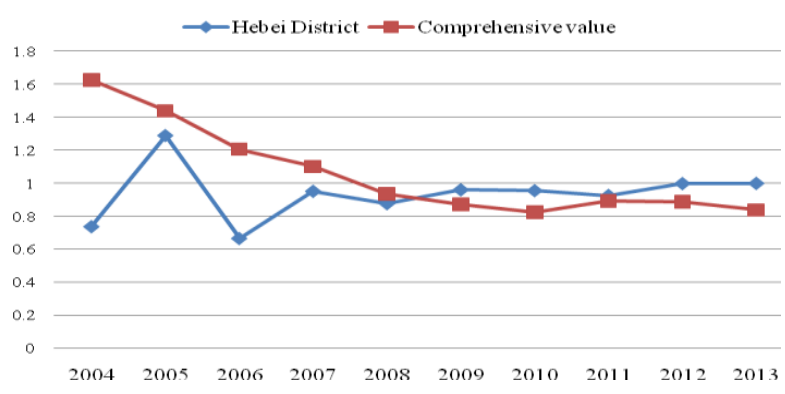

Figure 16. Hebei economic change and comparison

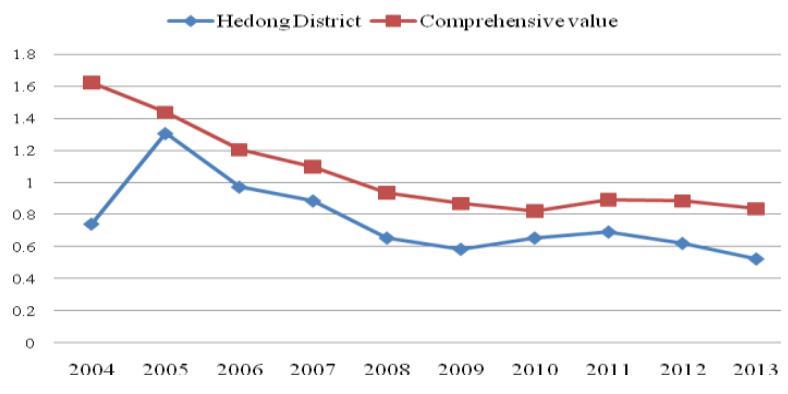

Figure 17. Hedong economic change and comparison 


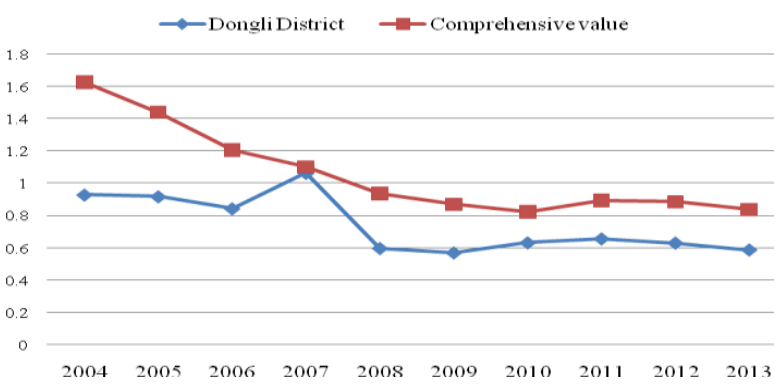

Figure 18. Dongli economic change and comparison

As shown in Figure 15-Figure 17, there are four counties which are Xiqing District, Hebei District, and East District, Dongli District and their average economic benefit is from thirteenth to sixteenth. The development of these four counties is relatively poor and their economic level lags behind other counties. 07 years ago, the economic benefit measurement value of Xiqing District is hovering in the Tianjin city's comprehensive efficiency values, in the 07 year, its economic value began to increase and it was almost the same to the comprehensive benefit value, between 08-11 years, it's development has improved, but in the 12 year, its development is falling, and in the 13 years, its development level is better than the comprehensive development level of Tianjin City; Between 04-07 years, the level of development of Hebei District fluctuated greatly, its trend is to increase and then decrease and then increase, it means that the economic development of Hebei District is very unstable in these years. 08 years later, its development began to become stable and its development trend has a little bit of rise, and it is above the level of integrated development; between 04-13 years, the Hedong District and the Dongli district economic development are lower than the comprehensive level. These four counties have many problems in their own development, it has dragged down the economic development of Tianjin City, so they need to focus on reform and implement the new policy.

\section{CONCLUSIONS}

This paper makes a comparative analysis of the economic benefits of sixteen counties in Tianjin City, contrasts the economic benefits of the counties and the comprehensive economic benefits of Tianjin City, obtains the economic development status of each county, and points out the shortcomings of them. From the 2004-2013 ten-year trend analysis and studies, it obtains that the economic development benefit of most counties is showing a downward trend then analyze this downward trends through the divisions of all counties.

\section{ACKNOWLEDGEMENTS}

This work is financially supported by National Natural Science Foundation of China (71271084, 71261017, 70961005) and Tianjin Education Commission of Social Sciences major projects (2012ZD35).

\section{REFERENCES}

[1] CHARNES A, COOPER, W W, RHODES e. Measuring the Efficiency of Decision - making Units [J]. European Journal of the Operational Research, 1978, 2 (6), 429-444.

[2] CHARNES A, W.W. COOPER Some Models for Estimating Technical and Scale Inefficiencies in Data Envelopment Analysis [J]. Journal of Management Science, 1984, 30 (9) : 1078-1092.

[3] CHARNES A, COOPER, W W, LI S.U sing Data Envelopment Analysis to Evaluate Efficiency in the Economic Performance of Chinese Cities [J]. Journal of Socio - Economic Planning Science, 1989, 23 (what?) : 325-34.

[4] COOPER W W, SEIFORD L M, THANASSOULIS E, ZANAKIS S. H. DEA and Its Uses in the company Countries [J]. European Journal of the Operational Research, 2004, 154 (2) : 337-344.

[5] Ma Zhan-xin. Data envelopment analysis model and the method [M]. Beijing: science press, 2010.

[6] Ma Zhan-xin, Wen Deer. Research on the Economic practice based on the Panel Data of Chinese Regions [C]. Proceedings of 2010 International Conference on Regional Management Sciences and Engineering, [s.n.] 2010:2010-369.

[7] Ma Zhan-xin. General reference set DEA model and its related properties [J]. Journal of systems engineering and electronics, 2012, (4) : 709-714.

[8] Ma Zhan-xin, the shavings. Nonparametric system analysis method based on empirical data evaluation [J]. Control and decision, 2012, 27 (2) : 199-204.

[9] Ma Zhan-xin, Ma Shengyun, Siqin gaowa. Data envelopment analysis and its application cases [M]. Beijing: science press, 2013.

[10] Ma Zhan-xin. The data envelopment analysis (dea) (4) : poset with data envelopment analysis (dea) [M]. Beijing: science press, 2013. 